\title{
Early Responses of VEGF during Acute Lung Injury Induced by Seawater Immersion after Open Chest Trauma
}

\author{
Xiao-hong Hua, ${ }^{a}$ Yun-you Duan ${ }^{b}$ Yi Li ${ }^{b}$ Zhi-qiang Xue \\ ${ }^{a}$ Academy of Military Medical Sciences, ${ }^{b}$ Department of Respiratory Medicine, PLA Naval General Hospital, and \\ 'Department of Thoracic Surgery, PLA General Hospital, Beijing, PR China
}

\section{Key Words}

Acute lung injury $\cdot$ Immersion, seawater $\cdot$ Open chest trauma $\cdot$ Vascular endothelial growth factor

\begin{abstract}
Background: Immersion in seawater after open chest trauma may induce acute lung injury. Higher osmotic pressure is one of the main characteristics of seawater. The effects of vascular endothelial growth factor (VEGF) on endothelial cell permeability and proliferation have been demonstrated in studies. The early responses and effects of the VEGF on acute lung injury induced by seawater immersion after open chest trauma (SWI-ALI) are unknown. Objective: To investigate the levels of VEGF and its receptors in SWI-ALI and further explore whether the levels of VEGFs are connected with the pathogenesis of SWI-ALI. Methods: We put dogs into group 'seawater' and group 'control'. The control group only suffered from open chest trauma, whereas the seawater group was exposed to seawater after trauma. The levels of total protein in plasma and bronchoalveolar lavage fluid were measured to calculate the pulmonary permeability index. $0,2,4,6$ and $8 \mathrm{~h}$ after open chest trauma, the plasma samples were collected to test the levels of VEGFs with ELISA kit. Western blotting and real-time RT-PCR were used to
\end{abstract}

measure the VEGF levels in lung. Results: Compared with control animals, plasma osmotic pressure, VEGF and sVEGFR1 significantly increased in plasma, while VEGF and VEGFR-2 significantly increased in seawater-immersion lung tissue. The levels of VEGF in plasma were significantly correlated with plasma osmotic pressure and pulmonary permeability index. Conclusion: Early release of VEGFs increases pulmonary vascular permeability and partially leads to the development of SWI-ALI. VEGFs may have a crucial role in the early onset of SWI-ALI.

Copyright $\odot 2009$ S. Karger AG, Basel

\section{Introduction}

Acute lung injury (ALI) can result from a direct insult in the lung or an indirect insult from other organs mediated through the systemic circulation [1]. ALI is characterized by enhancement of pulmonary permeability and severe interstitial edema [2]. Seawater is a mixture of various salts and water, which has a salinity of 35 parts per thousand. Compared with the environment within mammals, seawater has a higher osmotic pressure, a lower temperature and an abundance of salts [3]. Seawater immersion after open chest trauma may induce acute lung

\section{KARGER}

Fax +41613061234 E-Mail karger@karger.ch www.karger.com
(C) 2009 S. Karger AG, Basel

0025-7931/10/0796-0490\$26.00/0

Accessible online at:

www.karger.com/res
Yun-you Duan

Department of Respiratory Medicine, PLA Naval General Hospital

6 Fucheng Road

Beijing 100048 (PR China)

Tel. +8610 13381207 389, Fax +8610 6695 8340, E-Mail forever.lemon@ @163.com 
injury (SWI-ALI), and its severe form, acute respiratory distress syndrome (ARDS) [4]. It may further develop multiple organ dysfunction syndrome, a life-threatening complication [5].

Vascular endothelial growth factor (VEGF), a dimeric $46-\mathrm{kD}$ protein, is a vasodilator, endothelial cell-specific, multi-functional cytokine that induces the proliferation of endothelial cells, increases vascular permeability, and plays a pivotal role in the pathogenesis of asthma, emphysema, acute respiratory distress syndrome and lung cancer [6]. In healthy lung tissue, the levels of VEGF protein are 500 times higher than those found in plasma [7]. VEGF is mainly produced by epithelial cells, while endothelial cells are suggested to be its major target [8]. However, with acute systemic inflammatory responses, VEGF may be released by numerous cell types, including alveolar type II epithelial cells, alveolar macrophages, and polymorphonuclear neutrophils [9]. The biological activity of VEGF as both a growth factor and a permeability factor is dependent on its interaction with specific receptors. Two well-defined receptors are: VEGFR-1 (also occurring as a soluble form, sFlt), and VEGFR-2 (KDR) [10]. A wide variety of cells express VEGF receptors, including activated macrophages and alveolar type II epithelial cells $[11,12]$. Most of the angiogenic activities of VEGF, as well as its effects on vascular permeability, are mediated by its receptor VEGFR-2, while VEGFR-1, as a biological inhibitor of VEGF, blocks this edema effect [13]. The biological properties of VEGF as a permeability factor have led to interest in its role during SWI-ALI. Improvements in the identification and characterization of possible prognostic parameters will lead to an improvement in patient management [14]. However, the early responses and effects of the VEGF on the SWI-ALI are unknown. In the present study, we investigated the levels of VEGF and its receptors and further explore whether the levels of VEGFs are connected with the pathogenesis of SWI-ALI.

\section{Materials and Methods}

\section{Animal Models}

For all experiments, we used 16 healthy grown-up dogs, each weighing 15-20 kg. Dogs were purchased from Beijing KeYu animal cultivation center (The SCXF, Beijing, 2002), with no preference for sex. Dogs were housed in a conventional animal facility. Prior to experimental intervention, the dogs were allowed to acclimatize for at least 1 week in the animal facility to recover from transportation. All investigations involving experimental dogs were reviewed and approved by the institutional review board of
Beijing Naval General Hospital Animal Care and Use Committee. All animals received care in compliance with the Principles of Laboratory Animal Care formulated by the National Society for Medical Research, and the Guide for the Care and Use of Experimental Animals formulated by the National Council on Animal Care.

These animals were randomized into a 'seawater' (SW) group and control group, with 8 animals grouping each. The animals in the control group only suffered from open chest trauma, whereas those in the SW group were exposed to seawater after open chest trauma.

The dog model of SWI-ALI was performed as previously described in detail [4]. Briefly, all animals were anesthetized with intramuscular injection of ketamine $(20 \mathrm{mg} / \mathrm{kg})$. Anesthesia was continuously maintained with ketamine throughout the experiment. The incision, $0.5 \mathrm{~cm}$ in diameter, was made with a sharp instrument in the forth intercostal of the right chest to form the opened pneumothorax in all experimental animals. In group SW, seawater $(35 \mathrm{ml} / \mathrm{kg})$ was infused into the pleural cavity. Then the incision skins of all experimental animals were sutured in $10 \mathrm{~min}$. The right carotid artery was cannulated in every animals for measurement of mean arterial blood pressure. The right jugular vein was cannulated in every animal for drawing blood for analysis. The oxygen index $\left(\mathrm{PaO}_{2} / \mathrm{FiO}_{2}\right)$, a ratio of arterial partial pressure of oxygen $\left(\mathrm{PaO}_{2}\right)$ to fraction of inspired oxygen $\left(\mathrm{FiO}_{2}\right)$ of $\leq 300$ $\mathrm{mm} \mathrm{Hg}(40 \mathrm{Kp})$ is the standard to prove the success of the SWIALI model.

The experimental seawater was made according to the standard of the Third Institute of Oceanography of the State Ocean Bureau: osmotic pressure was $1,250-1,350 \mathrm{mmol} / \mathrm{l}, \mathrm{pH}$ was 8.20 , proportion was $1.05-1.06$. Laboratory temperature was $25^{\circ} \mathrm{C}$, man-made seawater temperature was $22^{\circ} \mathrm{C}$.

\section{Sample Collection}

Blood samples were collected at 0, 2, 4, 6 and $8 \mathrm{~h}$ after open chest trauma. Bronchoalveolar lavage (BAL) was performed by instilling $15 \mathrm{ml}$ of saline through the endotracheal tube and gently aspirating back at $8 \mathrm{~h}$ after trauma. This was repeated twice. Later, $8 \mathrm{~h}$ after trauma, the dogs received intracardiac injection of $15 \mathrm{ml}$ of $15 \% \mathrm{KCl}$ and then were sacrificed. The lungs were removed for immunohistochemistry. BALF and blood samples were centrifuged at 3,000 $\mathrm{g}$ for $10 \mathrm{~min}$, and the supernatant was stored at $-20^{\circ} \mathrm{C}$ until measurement of protein concentration. Lung samples were stored at $-80^{\circ} \mathrm{C}$ until use.

Assessment of Acute Lung Injury

The plasma osmotic pressure (POP) and electrolyte concentration were measured with blood samples collected at $0,2,4,6$ and $8 \mathrm{~h}$ after trauma. We measured the total protein concentration in BAL fluid and plasma collected at $8 \mathrm{~h}$ after trauma. We then calculated the protein concentration ratio of BAL/plasma, known as pulmonary permeability index (PPI).

Enzyme-Linked Immunosorbent Assay

VEGF and sVEGFR ${ }_{1}$ levels were determined in plasma samples using an ELISA kit (dogs VEGF/sVEGFR ${ }_{1}$; Sunbio, Beijing, China). An automatic multifunction microplate reader (Multiskan MK3, Thermo, USA) was used to read the value. Assays were performed in duplicate following the manufacturer's instructions. 
Table 1. Reference sequence and primer sequences used for the oligonucleotide

\begin{tabular}{llll}
\hline & Reference sequence & Sense primer & Antisense primer \\
\hline VEGF & AF133250 & $5^{\prime}$-gggctgctgtaatgatgagg-3' & $5^{\prime}$-gggaacgctccaggacttat-3' \\
VEGFR-2 & DQ269018 & $5^{\prime}$-atccacgactcagcat-3' & $5^{\prime}$-tgtcagtgtcccgatagaag-3' \\
GAPDH & NM001003142.1 & $5^{\prime}$-aacatcatcctgcttccac-3' & $5^{\prime}$-gaccacctggtcctcagtgt-3' \\
\hline
\end{tabular}

Table 2. The changes of VEGFs in plasma with timing (pg/ml) $(\mathrm{n}=8, \overline{\mathrm{x}} \pm \mathrm{s})$

\begin{tabular}{llllll}
\hline Groups & $0 \mathrm{~h}$ & $2 \mathrm{~h}$ & $4 \mathrm{~h}$ & $6 \mathrm{~h}$ & $8 \mathrm{~h}$ \\
\hline VEGF in control & $23.75 \pm 1.91$ & $26.02 \pm 2.59$ & $26.09 \pm 2.39$ & $28.06 \pm 3.65$ & $27.28 \pm 2.27$ \\
VEGF in SW & $23.32 \pm 2.03$ & $31.43 \pm 7.03$ & $38.91 \pm 4.75^{*, * *}$ & $57.89 \pm 12.69^{*, * *}$ & $63.46 \pm 10.16^{*, * *}$ \\
sVEGFR $_{1}$ in control & $0.56 \pm 0.07$ & $0.61 \pm 0.12$ & $0.69 \pm 0.27$ & $0.63 \pm 0.16$ & $0.61 \pm 0.13^{* *}$ \\
sVEGFR $_{1}$ in SW & $0.60 \pm 0.09$ & $0.81 \pm 0.15^{*, * *}$ & $1.04 \pm 0.21^{*, * *}$ & $1.61 \pm 0.28^{*, * *}$ & $1.92 \pm 0.32^{*, * *}$ \\
\hline
\end{tabular}

${ }^{*} \mathrm{p}<0.05$, compared with the control group; ${ }^{* *} \mathrm{p}<0.05$, compared with the onset $(0 \mathrm{~h})$ in the same group.

\section{Immunohistochemistry}

For immunohistochemistry, lung tissue slides $(5 \mu \mathrm{m})$ were pre-treated with $0.25 \%$ Triton X-100 for 5 min and blocked for endogenous peroxidase and biotin with $0.3 \% \mathrm{H}_{2} \mathrm{O}_{2}$. The slides were incubated with designated primary antibodies, with a dilution of 1:100 for VEGF (sc-80439; Santa Cruz Biotechnology, Santa Cruz, Calif., USA), for overnight at $4^{\circ} \mathrm{C}$, and then with a secondary antibody for $15 \mathrm{~min}$ at $37^{\circ} \mathrm{C}$. Detection was done by Avidin Biotin Complex system with 3-3 diaminobenzidine as chromogen from a Histostain-Plus Bulk Kit Invitrogen 2 Generation LAB-SA Detection System (Cat. No. 85-6643; Invitrogen, Carlsbad, Calif., USA) and DAB Kit (Cat. No. 00-2014; Invitrogen). Cell nuclei were counterstained with hematoxylin.

\section{Western Blotting to Determine the VEGF Protein Expression}

Products

After the sample of lung tissue lysate was available, the protein concentration from homogenized snap-frozen lung samples (8 from each group) was determined by the Bradford method. Equal amounts of protein in each sample were boiled in SDS sample buffer and subjected to SDS-PAGE. Proteins were transferred to nitrocellulose membranes. Nonspecific binding was blocked by incubation of membranes with $5 \%(\mathrm{w} / \mathrm{v})$ nonfat milk in PBS for $1 \mathrm{~h}$. PVDF were incubated with the designated primary antibodies (mouse monoclonal antibody against VEGF of dog, sc80439; Santa Cruz Biotechnology) at 1:1,000 dilution overnight at $4{ }^{\circ} \mathrm{C}$. The blot was washed with TBS-T containing $0.05 \%$ Tween 20 and incubated for $2-3 \mathrm{~h}$ at room temperature with horseradish peroxidase-conjugated goat anti-mouse (1:3,000 dilution) IgG (ZB-2301; Zhong Shan Biotechnology, Beijing, China). After washing, the blots were visualized with an enhanced chemiluminescence detection kit (ZLI-9032; Zhong Shan Biotechnology). We stripped and reprobed blots with antibody for $\beta$-actin as a control. Autoradiographs were quantified by using a densitom- eter (GS-690; Bio-Rad Laboratories) and normalized to the $\beta$-actin control.

\section{Real-Time RT-PCR to Detect mRNA Synthesis of Encoding \\ VEGFs}

Quantitative real-time RT-PCR analysis of the mRNA expression of VEGF and VEGFR-2 were performed on RNA isolated from frozen lung tissue. Total RNA of tissue was extracted by using the RNA Extraction Kit (RN0302; Biomed). Total RNA was quantified at 260 and $280 \mathrm{~nm}$, and sample integrity was checked by using $1 \%$ agarose gel electrophoresis. Total RNA $(2 \mu \mathrm{g})$ was converted to CDNA; the reaction volume contained: 5 units of Moloney murine leukaemia virus (MMLV) reverse transcriptase (Promega M170A) and $0.5 \mu$ g oligo deoxythymidine. The reaction continued for $1 \mathrm{~h}$ at $37^{\circ} \mathrm{C}$. Reverse transcriptase-generated cDNAs encoding VEGF and GAPDH (used as a control of RNA integrity and internal standard) were amplified by PCR. Amplification of $5 \mu \mathrm{l}$ of cDNA was performed using $0.2 \mathrm{nM}$ sense and antisense VEGF primers and 2.5 units of Taq polymerase. The oligonucleotide primer sequences are shown in table 1. Samples were amplified for 40 PCR cycles. A 5-ml aliquot from each PCR reaction was subjected to polyacrylamide gel electrophoresis and visualized by autoradiography. Their authenticity was confirmed by direct nucleotide sequencing. All real-time RT-PCR studies were performed at least 4 times, using lung RNA from different animals.

\section{Statistical Analyses}

All data are expressed as mean \pm standard deviation and were analyzed with SSPS 10.0 software. Two-way repeated measures analysis of variance (ANOVA) followed by Dunnett's test for multiple time points observation or Student's t test for single time point observation, and correlation among variables was assessed with Pearson's correlation analysis ( 2 -tailed). p values $<0.05$ were regarded as significant. 


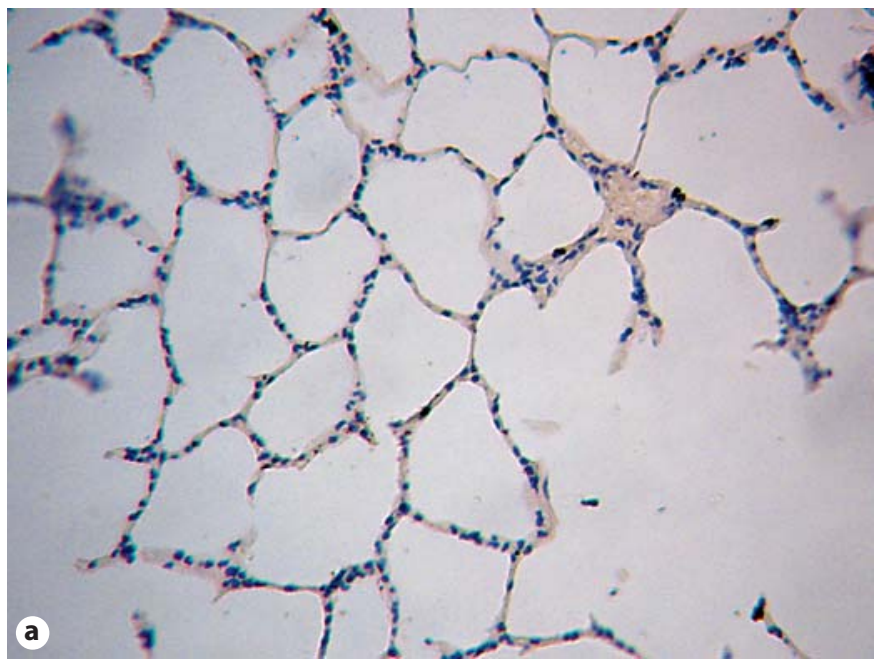

Fig. 1. Immunohistochemistry for VEGF in the lung. VEGF-positive expression in lung was stained brown. Sections of lung from control dogs (a) and SW dogs (b) are shown with immunohistochemistry. Figure 1 provides an overall impression of the changes of VEGF in different groups through the staining intensities in lung tissue. In control animal lungs (a), the alveolus structure retained its integrity, with mild capillary vessel congestion, there was little edema and few inflammatory cells in the alveolar spaces. The VEGF-positive reaction expression spot is less intense. In the SW animal lung tissue (b), there are visible interstitial and intra-alveolar edema and a greater area of VEGF-positive reaction expression. c The quantization value suggested that there was a significant difference between the SW and control groups $(27,744.75 \pm 5,222.84$ vs. $12,103.72 \pm 551.93, \mathrm{p}<0.05)$.

\section{Results}

\section{VEGF Expression Is Up-Regulated in the Early Onset} of SWI-ALI

Detection of Expression of VEGF and sVEGFR $_{1}$ in Plasma by ELISA

Expression patterns of VEGF and its soluble receptor $\left(\mathrm{sVGFR}_{1}\right)$ in plasma from both the control and seawater groups are shown in table 2. Plasma levels of the investigated molecules were increased with time after trauma. There is a negligible increase in control animals. A significant increase of the VEGF and sVEGFR 1 levels was found in the seawater group, especially at $4 \mathrm{~h}$ after trau$\mathrm{ma}$, and achieved their peak at 6-8 h. The increase was
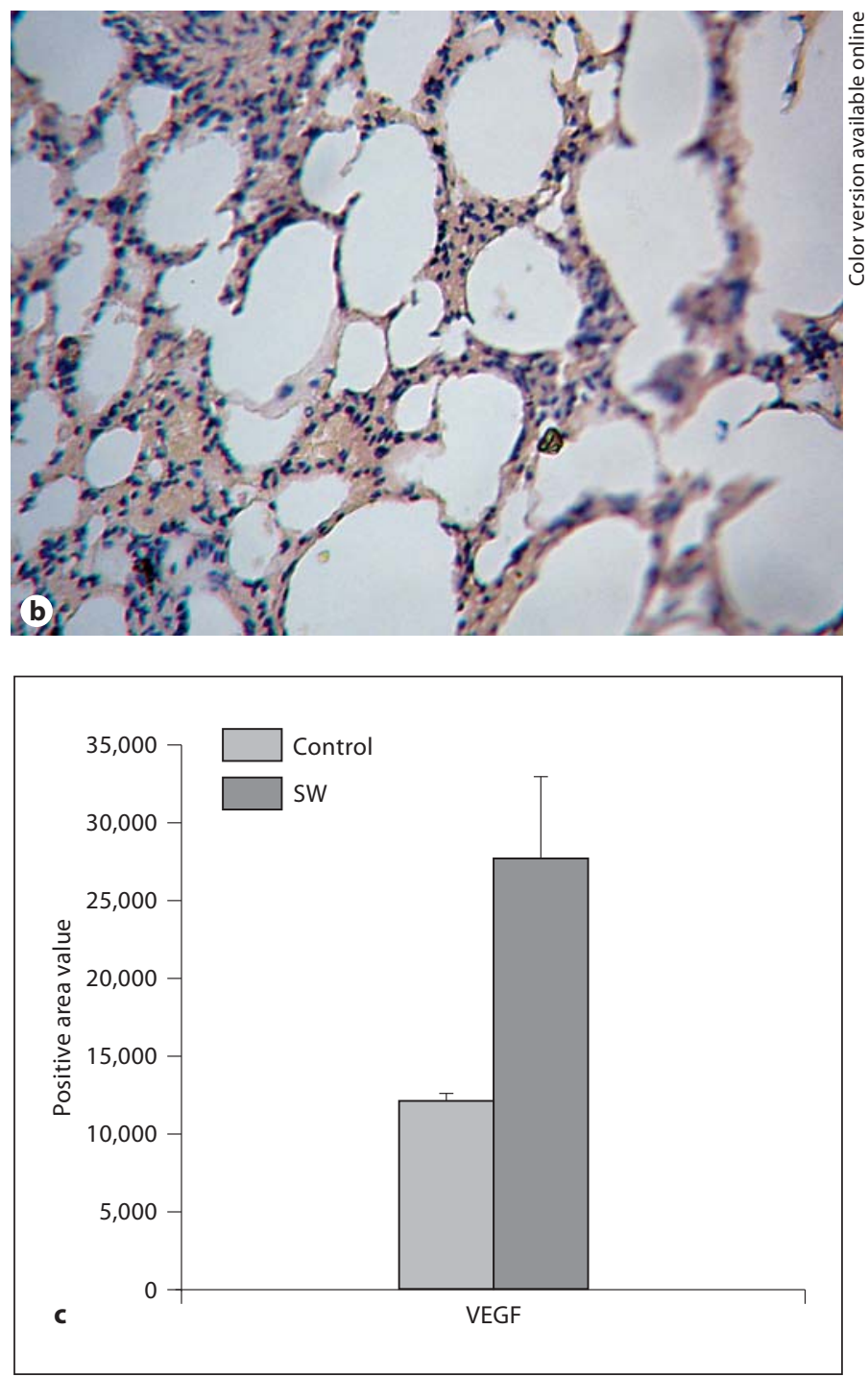

significantly greater than that in the control group $(\mathrm{p}<$ 0.05).

Detection of Expression of VEGF in Lung Tissue by Immunohistochemistry

Figure 1 provides an overall impression of the changes of VEGF in different groups through the staining intensities in lung. VEGF-positive expression in lung was stained brown. Figure 1a shows that, in control animal lungs, the alveolus structure retained its integrity, there was mild capillary vessel congestion, there was little edema and few inflammatory cells in the alveolar spaces. The VEGFpositive reaction expression spot is less intense. From figure $1 \mathrm{~b}$, in the SW animal model lungs, there are visible 


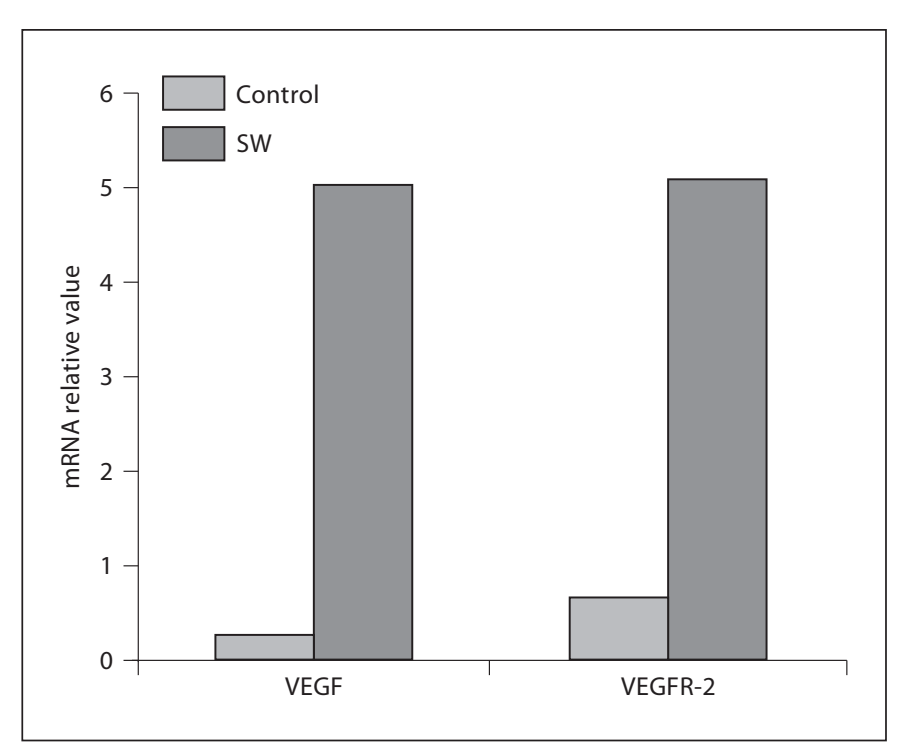

Fig. 2. Illustration of RT-PCR for VEGF/VEGFR-2 mRNA. The mRNA synthesis encoding VEGF and VEGFR-2 protein in lung tissue was significantly increased in the SW group. The VEGF mRNA: SW vs. control, $5.04 \pm 0.29$ vs. $0.25 \pm 0.04, \mathrm{p}<0.05$. VEGFR-2 mRNA: SW vs. control, $5.08 \pm 0.20$ vs. $5.08 \pm 0.20$, $\mathrm{p}<0.05$.

Table 3. VEGF mRNA and VEGF protein in the lung tissues $(\mathrm{n}=8, \overline{\mathrm{x}} \pm \mathrm{s})$

\begin{tabular}{llll}
\hline Group & $\begin{array}{l}\text { VEGF } \\
\text { mRNA (PCR) }\end{array}$ & $\begin{array}{l}\text { VEGFR-2 } \\
\text { mRNA (PCR) }\end{array}$ & $\begin{array}{l}\text { VEGF } \\
\text { (Western) }\end{array}$ \\
\hline Control & $0.25 \pm 0.04$ & $0.64 \pm 0.02$ & $0.1649 \pm 0.031$ \\
SW & $5.04 \pm 0.29^{*}$ & $5.08 \pm 0.20^{*}$ & $0.2375 \pm 0.036^{*}$ \\
\hline
\end{tabular}

${ }^{*} \mathrm{p}<0.05$, compared with the control group.

interstitial and intra-alveolar edema and greater area of VEGF-positive reaction expression. Figure 1c shows that the quantization value suggested that there was a significant difference between the SW and control groups $(27,744.75 \pm 5,222.84$ vs. $12,103.72 \pm 551.93, \mathrm{p}<0.05)$.

\section{Detection of mRNA Synthesis of Encoding VEGF}

Proteins in Lung Tissue by RT-PCR

The mRNA synthesis encoding VEGF and VEGFR-2 protein in lung tissue were significantly increased in the SW group (fig. 2, table 3). VEGF mRNA: SW versus control, $5.04 \pm 0.29$ versus $0.25 \pm 0.04, \mathrm{p}<0.05$. VEGFR-2 mRNA: SW versus control, $5.08 \pm 0.20$ versus $5.08 \pm$ $0.20, \mathrm{p}<0.05$.

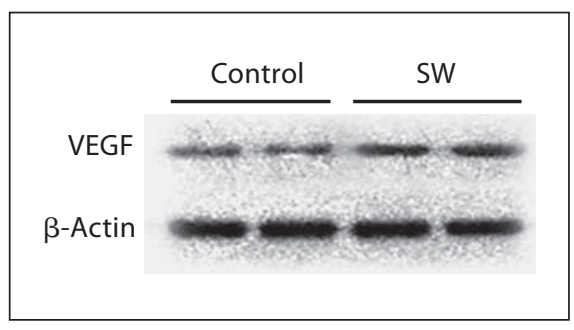

Fig. 3. Western blotting for VEGF protein. VEGF protein production in lung tissue. The optical density of blot bands were quantified with densitometry and normalized to that of actin as controls. The optical density of blot bands of VEGF protein in lung tissue in seawater group's animals is more concentrated than that in control animals. The quantization value suggested that there was a significant difference between the SW and control groups $(0.2375 \pm 0.036$ vs. $0.1649 \pm 0.031, \mathrm{p}<0.05)$.

\section{Detection of VEGF Protein in Lung Tissue by \\ Western Blotting}

VEGF protein production was determined in lung tissue (fig. 3, table 3). The optical densities of blot bands were quantified with densitometry and normalized to that of actin as controls. From the image in figure 3, we found that the optical density of blot bands of VEGF protein in lung tissue in SW animals is more concentrated than that in control animals. The quantization value suggested that there was a significant difference between the SW group and control group (SW vs. control, $0.2375 \pm$ 0.036 vs. $0.1649 \pm 0.031, \mathrm{p}<0.05)$.

\section{Detection of Degree of SWI-ALI}

The levels of $\mathrm{Na}^{+}, \mathrm{Cl}^{-}$and POP in plasma increased after immersion in seawater, attained homeostasis in $2 \mathrm{~h}$ after trauma and maintain it, which was significantly different from the control group $(\mathrm{p}<0.05)$.

We tested the protein concentration in plasma and BALF through the conventional laboratory. The total protein concentration in the BALF significantly increased in the SW group compared with the controls $(3.85 \pm 1.64$ $\mathrm{g} / \mathrm{l}$ vs. $1.95 \pm 0.57 \mathrm{~g} / \mathrm{l}, \mathrm{p}<0.05)$. PPI, which equates to total protein concentration ratio in the BALF/plasma, significantly increased in the SW group rather than that in control animals $(0.054 \pm 0.026$ vs. $0.025 \pm 0.007, p<$ 0.05).

\section{Correlation of VEGF with POP and PPI}

We assessed the correlations among the level of VEGF protein in plasma, the POP and PPI with Pearson's correlation analysis. POP was significantly positively correlated with PPI, with a Pearson's correlation coefficient of 
$0.681, p=0.004$. VEGF protein levels in plasma were significantly positively correlated with PPI and POP (VEGF with PPI correlation coefficient $=0.596, p=0.015$; VEGF with POP correlation coefficient $=0.917, \mathrm{p}=0.000$ ).

\section{Discussion}

Our experiment was the first attempt to investigate the levels of VEGF and its receptors in ALI induced by seawater immersion after open chest trauma. We chose dogs to duplicate SWI-ALI as they are a robust model that does not die quickly after trauma and seawater immersion. Further, large animals provide a model that is close to the clinical situation in humans.

We observed a significant increase of VEGF and sVEGFR $_{1}$ in plasma of SWI-ALI. Increased VEGF levels in plasma from our results agree with some studies in ARDS patients [15] or animal models of ALI induced by other etiologies [16, 17]. The mechanism of increased VEGF levels in plasma may be associated with the following 2 factors: one is that alveolar macrophages and neutrophils are both potential sources of VEGF in ALI, and the activated alveolar macrophages and neutrophils produce plentiful VEGF $[9,15,18]$; the other factor is that a widespread destruction of the alveolar epithelial membrane in ALI leads to increased VEGF through a transepithelial VEGF gradient [19]. We also found that the levels of VEGF and VEGFR-2 increased in the lung tissue of SWI-ALI. The results seem contrary to other studies. The down-regulation of VEGF has been noted in ARDS patients [16] and in the mouse lungs at 24 and $72 \mathrm{~h}$ after lipopolysaccharide injection [20]. There are 3 mechanisms to explain VEGF down-regulation during the critical phase of ALI. First, direct injury of alveolar epithelial cells and subsequent acute inflammatory responses may lead to cell death. As a result, death of alveolar epithelial cells may limit the production of VEGF in the lung [21]. Second, proteases released by the active neutrophils from acute inflammatory responses may cleave VEGF $[22,23]$. Third, the breached alveolar epithelium leads VEGF to plasma through a transepithelial VEGF gradient. Studies from animal models as well as from ARDS patients have shown that decreased levels of VEGF in the lung are associated with a worse prognosis $[21,24]$. Nevertheless, increases were noted not only in the VEGF protein levels (by Western blotting), but also the synthesis of mRNA encoding VEGF and VEGFR-2 protein (detected by real-time RT-PCR). So we speculate that the differences between our observation and other results may be explained by different timing after ALI/ARDS developed. Our present study was limited to the early onset of SWI-ALI, in the first 6-8 h. During the beginning of ALI, the activated alveolar macrophages and neutrophils produce plentiful VEGF in lung tissue [9], and the breach in the alveolar epithelium leads to VEGF being released from cytoplasm to the interstitial fluid [19]. These cause VEGF to be up-regulated in injured lung tissue. However, with the development of SWI-ALI, the levels of VEGF in the lung might decrease at the critical phase instead of increase at early-onset stage of SWIALI. This needs to be identified in our next work. In this study, we have detected, on the early onset of SWI-ALI, that the level of VEGF is up-regulated whether in plasma or in lung tissue.

The pleural space is a potential space within a closed environment. The volume of fluid in the pleural space is small, in the range of $0.2-0.5 \mathrm{ml}$. Mechanical disruption, or excess air, may induce inflammatory response and changes in the delicate environment. Inflammatory responses following the insult to the pleural space include release of chemokines to recruit neutrophils, mononuclear cells, and lymphocytes as well as the release of cytokines such as interleukin [25]. In our experiment, the levels of $\mathrm{Na}^{+}$and $\mathrm{Cl}^{-}$in plasma and POP increased soon after immersion in seawater, attained a homeostasis in $2 \mathrm{~h}$ after trauma, and maintain the state throughout the process. It has been shown that seawater immersion after open chest trauma might worsen the changes in the delicate homeostatic balance of the pleural space and lung, lead to serious injury of pleural mesothelium and lung parenchyma and increase the pulmonary permeability. Therefore, the PPI has a significant positive correlation with POP.

The increased VEGF in the plasma was significantly positively correlated with PPI. Lung over-expression of VEGF contributes to protein leakage in the lung and the development of pulmonary edema by changing the state of the adherens junction complexes on the endothelium [23], and increases lung vascular permeability. The increased VEGF in the plasma was also significantly positively correlated with POP. It suggests that this change may be related to higher osmotic pressure after seawater immersion. The environment of higher plasma osmotic pressure induced by seawater immersion worsens the lung injury through enhancing the VEGF level and the alveolus-capillary membrane permeability. Hence, we conclude that seawater, which is characterized by higher osmotic pressure and abundance of salts, contributes to the elevated VEGF and PPI, and further develops to SWI-ALI. 


\section{Conclusion}

This study has shown for the first time that increasing VEGF levels in intrapulmonary and plasma are associated with the early onset of SWI-ALI and elevated VEGF in plasma would be expected to contribute to abnormal capillary permeability. We speculate that significant and dynamic changes of the VEGF levels represent a marker of acute lung injury. VEGF may have diverse effects on different stages. We only collected plasma and lung tissue on the early onset of SWI-ALI and thus are unable to evaluate the levels and effects of VEGF on other phases of SWI-ALI. Therefore, further investigation is required to address the levels and effects of VEGF on other phases and to expound the intricate role of the VEGF system in SWI-ALI.

\section{Acknowledgments}

We thank Dr. Ning Hao-yong and Dr. Han Zhi-hai for technical support for this study. The authors thank the staff of the Animal Care Laboratory for their assistance with the experimental animals.

\section{References}

1 Pelosi P, Gattinoni L: Acute respiratory distress syndrome of pulmonary and extra-pulmonary origin: fancy or reality? Intensive Care Med 2001:27:457-460.

2 Wallace W, Donnefly SC: Pathogenesis of acute microvascular lung injury and the acute respiratory distress syndrome. Eur Resp Monograph 2002;20:22-32.

3 Pidwirny M: Physical and Chemical Characteristics of Seawater; in Pidwirny M (ed): Fundamentals of Physical Geography, ed 2, e-book. http://www.physicalgeography.net/ fundamentals/contents.html.

4 Meng J, Xue Z, Duan Y, et al: The empirical study of acute lung injury induced by seawater infusion following open chest trauma in dogs models. Chin J of Nautical Med and Hyperbaric Med 2008;15:74-77.

5 Yu J, Lai X, Li H, et al: Experimental study of survival time and mortality in war injuries complicated by seawater immersion. Med J Chin PLA 2005;30:268-269.

6 Voelkel NF, Vandivier RW, Tuder RM: Vascular endothelial growth factor in the lung. Am J Physiol Lung Cell Mol Physiol 2005; 290:209-221.

7 Kaner RJ, Crystal RG: Compartmentalization of vascular endothelial growth factor to the epithelial surface of the human lung. Mol Med 2001;7:240-246.

$\checkmark 8$ Ferrara N, Gerber HP, LeCouter J: The biology of VEGF and its receptors. Nat Med 2003;9:669-676.
9 Kaner RJ, Ladetto JV, Singh R, Fukuda N, Matthay MA, Crystal RG: Lung overexpression of the vascular endothelial growth factor gene induces pulmonary edema. Am J Respir Cell Mol Biol 2000;22:657-664.

10 Thickett DR, Armstrong L, Millar AB: A role for vascular endothelial growth factor in acute and resolving lung injury. Am J Respir Crit Care Med 2002;166:1332-1337.

${ }_{11}$ Brown KR, England KM, Goss KL, Snyder JM, Acarregui MJ: VEGF induces airway epithelial cell proliferation in human fetal lung in-vitro. Am J Physiol Lung Cell Mol Physiol 2001;281:L1001-L1010.

$>12$ Tsou R, Isik FF: Integrin activation is required for VEGF and FGF receptor protein presence on human microvascular endothelial cells. Mol Cell Biochem 2001;224:81-89

$\checkmark 13$ Gille H, Kowalski J, Li B, et al: Analysis of biological effects and signaling properties of Flt-1 (VEGFR-1) and KDR (VEGFR-2). A reassessment using novel receptor-specific vascular endothelial growth factor mutants. J Biol Chem 2001;276:3222-3230.

14 Geiser T: Single Gene Expression as a Prognostic Marker in Idiopathic Interstitial Pneumonia? Respiration 2008;76:251-252.

15 Thickett DR, Armstrong L, Christie SJ, Millar AB: Vascular endothelial growth factor may contribute to increased vascular permeability in acute respiratory distress syndrome. Am J Respir Crit Care Med 2001;164: 1601-1605.

16 Abadie Y, Bregeon F, Papazian L, et al: Decreased VEGF concentration in lung tissue and vascular injury during ARDS. Eur Respir J 2005;25:139-146.
17 Tsokos M, Pufe T, Paulsen F, Anders S, Mentlein R: Pulmonary expression of vascular endothelial growth factor in sepsis. Arch Pathol Lab Med 2003;127:331-335.

18 Gaudry M, Brégerie O, Andrieu V, El Benna J, Pocidalo MA, Hakim J: Intracellular pool of vascular endothelial growth factor in human neutrophils. Blood 1997;90:4153-4161.

19 Mura M, dos Santos CC, Stewart D, Liu M: Vascular endothelial growth factor and related molecules in acute lung injury. J Appl Physiol 2004;97:1605-1617.

20 Koehne P, Willam C, Strauss E, Schindler R, Eckardt KU, Bührer C: Lack of hypoxic stimulation of VEGF secretion from neutrophils and platelets. Am J Physiol Heart Circ Physiol 2000;279:H817-H824.

-21 Corne J, Chupp G, Lee CG, et al: IL-13 stimulates vascular endothelial cell growth factor and protects against hyperoxic acute lung injury. J Clin Invest 2000;106:783-791.

22 Ito Y, Betsuyaku T, Nagai K, Nasuhara Y, Nishimura M: Expression of pulmonary VEGF family declines with age and is further down-regulated in lipopolysaccharide(LPS)induced lung injury. Exp Gerontol 2005;40: 315-323.

23 Gamble JR, Drew J, Trezise L, et al: Angiopoietin-1 is an antipermeability and anti-inflammatory agent in vitro and targets cell junctions. Circ Res 2000;87:603-607.

24 Maitre B, Boussat S, Jean D, et al: Vascular endothelial growth factor synthesis in the acute phase of experimental and clinical lung injury. Eur Respir J 2001;18:100-106.

25 Jantz MA, Antony VB: Pathophysiology of the pleura. Respiration 2008;75:121-133. 